Sari Pediatri, Vol. 7, No. 2, September 2005: 73 - 76

\title{
Sindrom Wolff Parkinson White
}

\author{
Sri Endah Rahayuningsih
}

\begin{abstract}
Dilaporkan satu kasus sindrom Wolff-Parkinson-White pada anak laki-laki usia 9 tahun yang datang dengan keluhan utama palpitasi disertai nyeri dada. Elektrokardiogram pada awal masuk rumah sakit memperlihatkan frekuensi QRS 231 kali per menit $(\mathrm{N}$ : 60-100 $\mathrm{x} / \mathrm{m}$ ), gelombang $P$ tersembunyi dalam gelombang $T$ denyut sebelumnya, durasi QRS memanjang dan terdapat gelombang delta yang menunjukkan terdapat takikardia supraventrikular dengan aberrant conduction. Penderita mendapat pengobatan awal stimulasi vagal, tetapi tidak berhasil sehingga dilanjutkan dengan pemberian sotalol $3 \mathrm{x}$ $25 \mathrm{mg}$ per oral. Evaluasi elektrokardiogram menunjukkan irama sinus dengan gelombang delta yang sesuai dengan sindrom Wollf Parkinson White yaitu adanya perubahan frekuensi jantung menjadi 80-90 x/menit, tampak gelombang $\mathrm{T}$ dan $\mathrm{P}$ dengan interval PR memendek, durasi QRS melebar, dan terdapat gelombang delta. Prognosis pasien baik karena pada pengamatan elektrokardiografi tiap 24 jam terlihat irama jantung kembali menjadi irama sinus.
\end{abstract}

Kata kunci: sindrom Wolff-Parkinson-White, sotalol

ๆ akikardia supraventrikular (TSV) adalah satu jenis takidisritmia yang meliputi irama cepat yang timbul dari atrium, hubungan atrioventrikular, atau jalur tambahan. Kejadian TSV merupakan jenis distritmia yang paling sering ditemukan pada usia bayi dan anak dibandingkan dengan takidisritmia lainnya, dengan angka kejadian kurang lebih 1 : 25.000 anak normal. Lebih sering terjadi pada anak laki-laki dari pada perempuan. Terjadinya TSV disebabkan oleh dua mekanisme dasar, yaitu ektopik (automatic) dan re-entry (dengan atau tanpa jalur tambahan). Pasien dengan jalur tambahan sering diakibatkan oleh sindrom Wolff-Parkinson-White

\footnotetext{
Alamat korespondensi:

Sri Endah Rahayuningsih, dr., Sp.A

Bagian/SMF Ilmu Kesehatan Anak FKUP/RSUP dr. Hasan Sadikin

Jl. Pasteur No. 38, Bandung 40161.

Telp./Fax. 2034426-203595
}

(sindrom WPW). Naskah ini melaporkan seorang anak dengan sindrom Wolff-Parkinson-White.

\section{Kasus}

Seorang anak laki-laki berusia 9 tahun datang ke Instalasi Gawat Darurat Dr. Hasan Sadikin Bandung dengan keluhan utama jantung berdebar yang semakin lama semakin terasa hebat, disertai dengan nyeri dada sebelah kiri yang dirasakan sejak 4 hari sebelum masuk rumah sakit, tanpa disertai sesak nafas, demam maupun sinkop.

Dari pemeriksaan fisis ditemukan berat badan 23 $\mathrm{kg}$, tinggi badan $139 \mathrm{~cm}$, dengan rasio BB/TB $80 \%$ (NCHS), tampak sadar, tidak tampak sianosis, tekanan darah 90/60 $\mathrm{mmHg}$, frekuensi jantung $210 \mathrm{x} / \mathrm{m}$, regular, ekual, frekuensi pernafasan $30 \mathrm{x} / \mathrm{m}$, regular, suhu badan $36,0^{\circ} \mathrm{C}$. Pemeriksaan fisis lain dalam batas normal. Hasil pemeriksaan laboratorium menunjukkan kadar hemoglobin, leukosit, trombosit dan hematokrit, elektrolit (natrium dan kalium), fungsi 
ginjal (ureum dan kreatinin) dalam batas normal. Hasil pemeriksaan CPK dan CKMB untuk mendeteksi adanya miokarditis juga dalam batas normal. Foto toraks menunjukkan kardiomegali (rasio jantung toraks 58\%). Elektrokardiogram pada awal masuk memperlihatkan frekuensi QRS 231 x/m (N: 60-100 $\mathrm{x} / \mathrm{m}$ ), gelombang $\mathrm{P}$ tersembunyi dalam gelombang $\mathrm{T}$ denyut sebelumnya, durasi QRS memanjang yaitu 0,1" (Normal:0,07"-0,09"), dan terdapat gelombang delta. Disimpulkan bahwa pemeriksaan elektrokardiogram menunjukkan takikardia supraventrikular dengan aberrant conduction (Gambar 1)

Pemeriksaan ekokardiografi memperlihatkan intrakardiak dalam batas normal dengan fungsi ventrikel kiri normal. Pasien mendapat pengobatan awal stimulasi vagal, dan ternyata tidak berhasil. Elektrokardiogram tetap menunjukkan takikardia supraventrikular dengan abberant conduction (Gambar 2)

Selanjutnya pasien diberi sotalol 3 x $25 \mathrm{mg}$ per oral. Setelah pemberian sotalol tampak perubahan pada gambaran elektrokardiogram yaitu, terdapat perubahan frekuensi jantung menjadi 80-90x/menit, tampak gelombang $\mathrm{T}$ dan $\mathrm{P}$ dengan interval $\mathrm{PR}$ memendek, durasi QRS melebar, dan terdapat gelombang delta (Gambar 3). Disimpulkan bahwa pemeriksaan elektrokardiogram menunjukkan irama sinus dengan gelombang delta yang sesuai dengan sindrom Wollf Parkinson White (sindrom WPW)

Setelah irama sinus tercapai, dosis sotalol diturunkan menjadi 2 X $25 \mathrm{mg}$ per oral per hari. Pengamatan elektrokardiografi tiap 24 jam memperlihatkan irama jantung sesuai dengan irama sinus. Pada evaluasi 1 bulan setelah pemberian sotalol, elektrokardiogram tetap menunjukkan irma sinus

\section{Diskusi}

Takikardia supraventrikular (TSV) adalah satu jenis takidistritmia yang meliputi setiap irama cepat yang timbul dari atrium, hubungan atrioventrikular atau

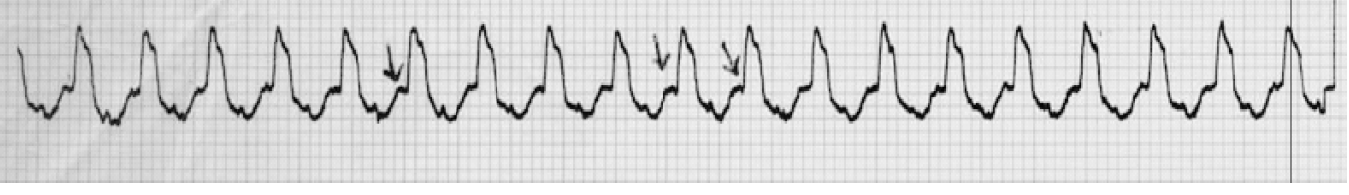

Gambar 1. Elektrokardiogram menunjukkan takikardia supraventrikular dengan abberant conduction

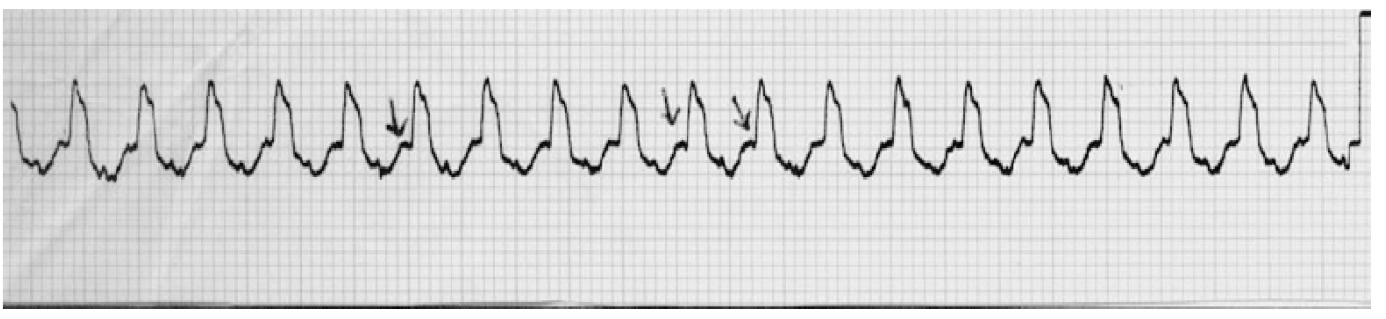

Gambar 2. Elektrokardiogram setelah dilakukan manuver vagal

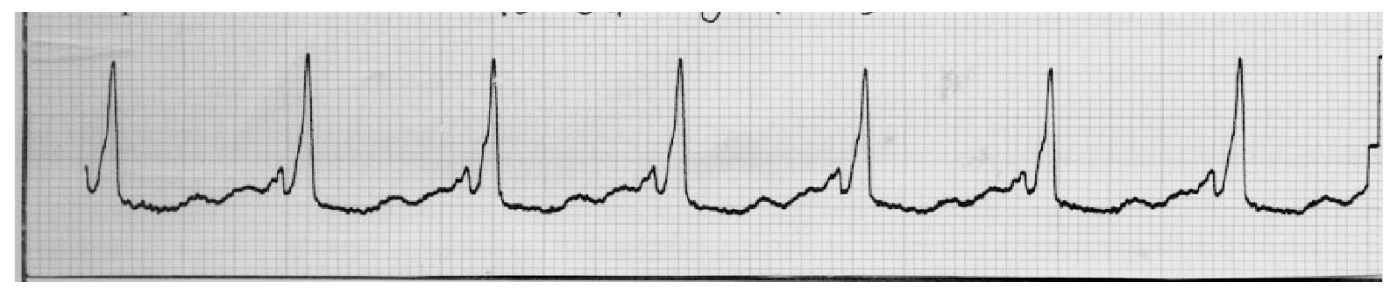

Gambar 3. Elektrokardiogram setelah pemberian sotalol 
jalur tambahan. ${ }^{1}$ Atau dengan kata lain takikardia supraventrikular didefinisikan sebagai suatu mekanisme disritmia yang abnormal yang timbul di atas atau pada bundle his. ${ }^{2,3}$ Frekuensi jantung mendadak bertambah cepat, berkisar antara 180-300 kali permenit. Kelainan TSV merupakan jenis distritmia yang paling sering ditemukan pada usia bayi dan anak dibandingkan dengan takidisritmia lainnya, dengan angka kejadian kurang lebih $1: 25.000$ anak normal. Lebih sering terjadi pada anak laki-laki daripada perempuan. Kejadian TSV disebabkan oleh dua mekanisme dasar yaitu ektopik (automatic) dan re-entry (dengan atau tanpa jaras tambahan). Pasien dengan jaras tambahan (accessory pathway atau atrio-ventricular connection) dapat mengkonduksi impuls dari atrium ke ventrikel atau sebaliknya. Pada orang normal jaras tambahan ini sering tidak ditemukan, dan konduksi antara atrium dan ventrikel hanya dihubungkan oleh sistim konduksi normal melalui nodus AV yang terletak di septum interatrium bagian bawah, di trigonum Koch (segitiga yang dibatasi oleh tendon Todaro, bagian septum katup trikuspid dan bagian dasarnya oleh os sinus coronarius). Jaras tambahan umumnya terletak di batas antara atrium dan ventrikel yang dikenal dengan $A V$ groove. , $^{4,6}$

Berdasarkan sifat konduksinya, maka jaras tambahan dapat dibagi menjadi 3 jenis. Jenis pertama adalah jaras tambahan yang dapat mengkonduksi secara antegrad dan retrograd, merupakan jenis yang paling sering dijumpai. Jenis kedua adalah jaras tambahan yang hanya mengkonduksi secara retrograd saja. Sedang yang ketiga adalah yang hanya mengkonduksi secara antegrad saja, paling jarang dijumpai. Bilamana jaras tambahan dapat mengkonduksi secara antegrad, akan memberikan gambaran elektrokardiogram sebagai gelombang delta oleh karena ventrikel tereksitasi tidak hanya melalui jaras normal (nodus AV dan sistim hispurkinye) tetapi juga melalui jaras tambahan yang datangnya lebih awal dari yang normal. Eksitasi sebagian otot jantung, apakah di ventrikel atau atrium yang lebih awal daripada semestinya dikenal dengan pre-eksitasi. Gambaran elektrokardiogram berupa gelombang delta, interval PR yang pendek yang dikenal sebagai sindrom WPW, dan terjadi pada $10-20 \%$ kasus TSV. $4,5,6$

Manifestasi klinis sindrom WPW adalah palpitasi, nyeri dada, gelisah, takipne, penurunan intoleransi latihan, dan dapat menimbulkan gagal jantung. ${ }^{5}$ Pada pasien ini ditemukan keluhan jantung berdebar cepat (palpitasi) disertai nyeri dada, tanpa disertai pingsan. Pemeriksaan fisis menunjukkan anak sadar, tidak tampak sesak, frekuensi jantung sangat cepat yaitu 210 kali permenit.

Kriteria diagnosis sindrom WPW ditegakkan berdasarkan ${ }^{4,5}$

1. Pemendekan interval PR, di bawah batas normal sesuai usia, yaitu

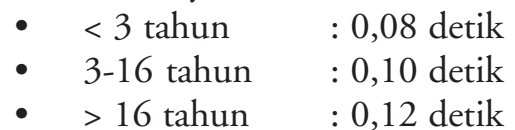

2. Gelombang delta (slurred awal kompleks QRS)

3. Durasi QRS melebar lebih dari batas normal

Gambaran EKG pada pasien ini menunjukkan frekuensi QRS 231 x/m (N: 60-100 x/m), gelombang $P$ tersembunyi dalam gelombang $\mathrm{T}$ denyut sebelumnya, durasi QRS memanjang yaitu 0,1" (normal: 0,07"-0,09") dan terdapat gelombang delta. PR interval yang memendek tidak dapat dilihat karena gelombang $\mathrm{P}$ bertumpuk dengan gelombang $\mathrm{T}$. Sehingga pada awal didiagnosis sebagai takikardia supraventrikular dengan aberrant conduction. Setelah pemberian sotalol tampak durasi QRS melebar, gelombang $\mathrm{P}$ mulai tampak dan terdapat gelombang delta (Gambar 3). Kesan elektrokardiogram adalah irama sinus dengan gelombang delta yang sesuai dengan sindrom WPW. Beberapa kepustakaan menyatakan bahwa diagnosis sindrom WPW baru dapat ditegakkkan setelah gambaran elektrokardiogram kembali ke irama sinus. ${ }^{5}$

Aritmia adalah keadaan yang memerlukan penanganan segera karena dapat menyebabkan gangguan perfusi jantung yang pada akhirnya akan mengganggu perfusi sistemik. Prinsip umum tata laksana aritmia adalah penanganan terhadap keadaan umum pasien, penanganan terhadap segala hal yang dapat memperburuk aritmia, penanganan terhadap penyebab aritmia, evaluasi hemodinamik secara ketat pada pemberian obat antiaritmia, karena sebagian besar obat antiaritmia akan menyebabkan penurunan kontraksi miokardium. Penanganan kasus sindrom WPW dilakukan dengan tindakan manuver vagal, pemberian â-bocker untuk menghalangi nodus AV, dan mungkin hantaran jalur tambahan dan untuk mengurangi denyut jantung prematur yang berperan sebagai pemicu, obat-obat antiaritmia kelas IA, IC atau 
kelas III, ablasi jaras tambahan secara bedah atau kateter. ${ }^{3,4}$ Digoksin tidak boleh digunakan pada kasus sindrom WPW karena dapat menimbulkan konduksi antegrad jaras tambahan. Pasien sindrom WPW lebih rentan terhadap timbulnya fibrilasi atrium atau flutter, sehingga pemberian digoksin berisiko menimbulkan konduksi 1:1 pada ventrikel dan dan menimbulkkan takikardia dan fibrilasi ventrikel. ${ }^{4}$

Manuver vagal yang dilakukan pada pasien ini tidak berhasil dan selanjutnya diberikan sotalol 3 kali 1-2 $\mathrm{mg} / \mathrm{kgBB} /$ dosis, setelah tercapai irama sinus dipertahankan dengan dosis $2 \times 25 \mathrm{mg}$ per oral. Selama pemantauan dan setelah pemberian sotalol, keadaan klinis pasien maupun gambaran elektrokardiogram membaik. Sotalol merupakan golongan â-bloker (nonselektif) pada dosis rendah, tetapi juga menunjukkan aktivitas sebagai antiaritmia kelas III pada dosis tinggi. Sotalol menyebabkan pemanjangan periode refrakter pada atrial dan jaringan ventrikel, juga mempengaruhi durasi potensial aksi dari serabut Purkinye. Sotalol efektif untuk takikardia supraventrikular termasuk atrial flutter dan takikardia ventrikular; tidak larut dalam lemak sehingga tidak mengalami metabolisma di hepar. Efek sampingnya dapat menyebabkan bradikardia dan blok AV, eksaserbasi gagal jantung kongestif., 3

Prognosis jangka panjang, dengan adanya jaras tambahan sangat bervariasi. Bila sindrom WPW simptomatik terjadi pada bayi, maka dapat mengalami kekambuhan. ${ }^{3,4}$

Walaupun demikian sebagian kecil kasus sindrom WPW yang tidak teratasi dapat mengalami henti jantung dan kematian mendadak. Salah satu kepustakaan menyebutkan insidens kematian mendadak sindrom WPW berkisar antara 1-2 /1000 kasus tiap tahun. ${ }^{3,4}$

Prognosis pasien ini baik, karena dengan pemberian sotalol, TSV menunjukkan perbaikan gejala klinis dan gambaran elektrokardiogram. Pasien sudah cukup besar, dapat dilakukan pemeriksaan elektrofisiologi dan dilanjutkan dengan ablasi pada jaras tambahan.

\section{Daftar Pustaka}

1. Walsh EP, Saul JP. Cardiac arrhytmias. Dalam: Fyler DC, penyunting. Nadas'Pediatric Cardiology. Philadelphia: Mosby; 1992. h. 377-433.

2. Hay WW, Howard AR, Levin MJ, Sondheimer JM. Disorders of rate $\&$ rhythm $\&$ of electrolyte imbalance. Dalam: Hay WW, Howard AR, Levin MJ, Sondheimer JM, penyunting. Current pediatric diagnosis \& treatment. Edisi ke-16. New York:Mc. Grow Hill; 2003. h. 599-613.

3. Dubin A. Cardiac arrhytmias. Dalam: Behrman RE, Kliegman RM, Jenson HB, penyunting. Nelson textbook of Pediatrics. Edisi ke-17. Philadelphia:WB. Saunders; 2004. h. 1554-65.

4. Perry JC. Supraventricular tachycardia. Dalam: Garson A Jr, Bricker JT, Fisher DJ, Neish SR, pennyunting. The science and practice of pediatric cardiology. Edisi ke-2. Philadelphia: Williams \& Wilkins; 1998. h. 2059-101.

5. Park MK, Troxler RG. Cardiac arrhytmias. Dalam: Park MK, Troxler RG, penyunting. Pediatric cardiology for practioners. Edisi ke-4. St. Louis: Mosby; 2002. h. 33348.

6. Perry JC, Walsh EP. Diagnosis and management of cardiac arrhythmias. Dalam: Chang AC, Hanley FL, Wernovsky G, Wessel DL, penyunting. Pediatric cardiac intensive care. Baltimore: Williams \& Wilkins; 1998. h. 461-81.

7. Fish FA, Benson DW. Disorders of cardiac rhythm and conduction. Dalam: Allen HD, Gutgessell HP, Clarck EB, Driscoll DJ, penyunting. Moss and Adams' heart disease in infants, children, and adolescent including the fetus and young adult. Edisi ke-6. Philadelohia: Lippincott Williams \& Wilkins, 2001. h. 482-533. 